\title{
Evaluation of Epidemiological Determinants Influencing Measles among Children with History of Measles Vaccination
}

\author{
Pravin Munde, Dipika Shrestha*, Ratnendra Shinde
}

Pravin Munde, Dipika Shrestha*, Ratnendra Shinde

Department of Community Medicine, Seth G.S.M.C, KEM Hospital, Parel, Mumbai, Maharashtra, INDIA.

\section{Correspondence}

Dr. Dipika Shrestha

Flat 401, Park Vista Bldg., 10 $0^{\text {th }}$ Road, Khar (W), Mumbai- 52, Maharashtra, INDIA.

Mobile no: +919664061167

Email: dipikashrestha@gmail.com

History

- Submission Date: 31-07-2017

- Revised Date: 30-03-2018

- Accepted Date: 13-09-2018

DOI : 10.5530/ijmedph.2018.3.25

Article Available online

http://www.ijmedph.org/v8/i3

\section{Copyright}

(C) 2018 Phcog.Net. This is an openaccess article distributed under the terms of the Creative Commons Attribution 4.0 International license.

\begin{abstract}
Background: Measles has been a major public health concern leading to death among children despite availability of safe and cost-effective vaccines. Global push to improve vaccine coverage resulted in an $84 \%$ reduction in deaths. However, data from the year 2016 still reveals that there were 89, 780 measles deaths globally. ${ }^{1}$ Aim: To study the epidemiological determinants influencing measles in children previously immunized with measles vaccine. Objectives: To determine the proportion of measles infected cases with history of prior measles immunization. To compare clinical profile of patients with and without history of prior measles immunization. Setting and design: Record based, Retrospective Cross sectional Study. Materials and Methods: A retrospective study was conducted using hospital records from an infectious disease hospital situated in Greater Mumbai. The study was carried out over duration of 1 year. Records of all cases admitted for measles from January 2013 to December 2013 were studied in detail. Sampling technique used was universal sampling. Total sample size was 471 . Majority of the cases were admitted based on the WHO clinical definition while for a few suspicious cases Measles specific IgM was carried out. Statistical analysis used: Chi square test. Results: Out of 471 case records reviewed for measles, $47 \%$ children were vaccinated for measles. Percentage of undernourished children who received the immunization was $48 \%$. A statistically significant association was observed for age, gender and duration of disease amongst those who were immunized for measles $(p<0.01)$. Conclusion: A significant percentage of children despite immunization suffered from measles. Age, gender and nutrition were found to play a vital role in acquisition of measles both in the vaccinated and unvaccinated children.

Key words: Retrospective study, Record based, Measles immunization.
\end{abstract}

\section{INTRODUCTION}

Measles is an acute viral infection caused by a virus belonging to Paramyxovirus family. As per WHO, there were 1,22,000 measles deaths globally in 2012. ${ }^{2}$ That means 330 deaths every day and 14 deaths every hour, the majority ( $85 \%$ ) of which are reported from Asia. Also, about $84 \%$ world's children received one dose of measles vaccine by their first birthday. ${ }^{1}$ The live attenuated measles vaccine is believed to be safe, effective and provide long-lasting protection with a vaccine efficacy of 85 to $90 \%$ when given at the age of 9-11 months. Despite increased coverage of measles vaccination with effective vaccine, morbidity due to measles was still found to be high. Studies have been carried out in Nigeria by Faneye AO et al. where in 143 (62.4\%) children who were admitted for measles, of these, 79 (55.3\%) had been vaccinated for measles, while 65 (44.7\%) had not. In another study by Nkowane BM et al. reveals a measles outbreak amongst vaccinated school children in a city near Boston. ${ }^{3,4}$

This study strives to investigate clinical profile of patients who contracted measles infection despite history of measles vaccination. Also, compare profile of vaccinated and non-vaccinated patients who suffered from measles. Thus enabling us to identify determinants influencing occurrence of measles amongst vaccinated children.

\section{OBJECTIVES}

1. To determine the proportion of measles infected cases with history of prior measles immunization.

2. To study and compare the clinical profile of patients with and without history of prior measles immunization.

\section{MATERIALS AND METHODS}

A cross-sectional retrospective study was conducted using hospital records from an infectious disease hospital situated in Greater Mumbai. The study was carried out over duration of 1 year. Records of all admitted measles cases from January 2013 to December 2013 were studied in detail. Sampling technique used was universal sampling. Total sample size was 471 .

Details of age, sex, number of complications, history of immunization, duration of hospital stay, investigations done, history on vitamin A administration in the hospital was collected from the hospital records.
Cite this article : Munde P, Shrestha D, Shinde R. Evaluation of Epidemiological Determinants Influencing Measles among Children with History of Measles Vaccination. Int J Med Public Health. 2018;8(3):116-8. 


\section{Inclusion Criteria}

Case records of pediatric children below 12 years admitted during January 2013 to December 2013 with clinical measles diagnosed by trained physician.

Clinical case definition (WHO)- any person in whom a clinician suspects measles infection or any person with fever and maculopapular rash (i.e. non-vesicular) and cough, coryza (i.e. runny nose) or conjunctivitis (i.e. red eyes)

\section{Exclusion Criteria}

1. Incomplete and unreliable case records i.e. case records on which measles vaccination status is not mentioned.

2. Patients who were clinically diagnosed as measles and who had taken discharge against medical advice.

Data was entered using Microsoft-Excel 2011 Software and analyzed by using SPSS Software version 21.0. Chi Square test was used to demonstrate statistical association between the variables in the study.

\section{RESULTS AND DISCUSSION}

Out of a total of 471 measles cases, percentage of vaccinated cases (47\%) is almost equal to unvaccinated cases (53\%). Indicative of increasing cases among previously immunised patients. Similar findings was observed by R. Ganesh and T. Vasanthi. ${ }^{2,5}$ Most likely due to Ineffective vaccines and waning of vaccine immunity with time. (Table 1 )

The number of measles cases among children who were vaccinated was found to be significantly higher after the age of 1 year $(n=199, p<0.01$, Table 1) which was similar to earlier study by Sharma, et al. ${ }^{6}$ This calls for stringent implementation of quality immunization practices along with quality nutrition, hygiene, sanitation and safe water provisions. Also high maternal antibody levels can alter immunization response to first dose of measles vaccine at 9 months and its subsequent effect on response to MMR at 16-18 months, as stated in an article "Time to rethink measles vaccination schedule in India", by T. Jacob John and Valson P Verghese

A significant association was noted amongst measles cases in vaccinated female children $(P<0.01$, Table 1$)$. The ratio of measles cases female: male is 1.15:1. A significantly higher number of vaccinated female children with measles were admitted as compared to vaccinated male cases. This may be due to higher prevalence of under nutrition in female child.

Proportion of undernourished cases admitted for measles $(n=371,67 \%)$ was higher than those who had a normal nutritional status, indicating that poor nutrition can be a predisposing factor to measles as it reduces immunity to fight infections. However, this finding was not found to be statistically significant ( $>00.05$, Table 1$)$. Similar finding was mentioned in report of Director General, WHO in 1995, "Bridging the gaps" which stated that along with need for quality routine immunizations we must also strengthen immunity by providing quality supplementary nutrition, growth chart monitoring and timely intervention. ${ }^{7}$

Complications following measles were found to be significantly higher in those who were unvaccinated than those who were vaccinated for the same $(P<0.01$, Table 1$)$. This finding was similar with study of Ashok Mishra et al. where in 94 cases presented with pneumonia, 2 with convulsions, 2 with pneumonia and convulsions, 1 with meningitis, 1 with hepatitis and 3 deaths, all of which were among unvaccinated group of children admitted for measles. ${ }^{8}$

A highly significant association between duration of disease and vaccination status among cases of measles was observed $\left(\mathrm{X}^{2}=250.5, p<0.01\right.$, Table 2). In majority of the measles cases that were vaccinated the duration of disease did not exceed 8 days $(P<0.01$, Table 1$)$. Among the unvaccinated cases the duration of disease over 8 days was significantly higher than those children who were vaccinated for measles. Similar findings were observed in a study by Mitchell $\mathrm{P}$ et al. where in vaccination modified the clinical duration amongst children who suffered from measles. ${ }^{9}$

Pneumonia was the commonest complication seen in 67 (27\%) nonvaccinated cases which was 29 (13\%) in vaccinated cases. (Table 2) No death was seen in cases with history of measles vaccination, was the prime encouraging outcome for measles vacination. A similar study was seen by CR Sudfield et al. where in pneumonia was found to be the most common complication among the unimmunized children for measles. ${ }^{10}$

\begin{tabular}{|c|c|c|c|c|c|}
\hline Criteria & Subcategory & $\begin{array}{c}\text { Vaccinated } \\
\text { Cases }\end{array}$ & Not vaccinated & Total & P value \\
\hline \multirow[t]{3}{*}{ Age } & $<1$ year & $21(24 \%)$ & $67(76 \%)$ & $88(100 \%)$ & \multirow{3}{*}{$\begin{array}{l}0.0000001 \\
\left(X^{2}=43.22\right)\end{array}$} \\
\hline & $1-5$ years & $115(44 \%)$ & $146(56 \%)$ & $261(100 \%)$ & \\
\hline & $>5$ years & $84(55 \%)$ & $38(45 \%)$ & $152(100 \%)$ & \\
\hline \multirow[t]{2}{*}{ Gender } & Male & $88(40 \%)$ & $131(60 \%)$ & $219(100 \%)$ & \multirow{2}{*}{$\begin{array}{c}0.0081 \\
\left(\mathrm{X}^{2}=7.004\right)\end{array}$} \\
\hline & Female & $132(84 \%)$ & $120(16 \%)$ & $252(100 \%)$ & \\
\hline \multirow[t]{2}{*}{ Nutrition } & Normal & $70(45 \%)$ & $87(55 \%)$ & $157(100 \%)$ & \multirow{2}{*}{$\begin{array}{c}0.5137 \\
\left(\mathrm{X}^{2}=0.426\right)\end{array}$} \\
\hline & Undernourished & $150(48 \%)$ & $164(52 \%)$ & $314(100 \%)$ & \\
\hline \multirow[t]{2}{*}{ Complications } & Present & $163(41 \%)$ & $230(59 \%)$ & $393(100 \%)$ & \multirow{2}{*}{$\begin{array}{l}0.0000003 \\
\left(X^{2}=26.11\right)\end{array}$} \\
\hline & Absent & $57(73 \%)$ & $21(27 \%)$ & $78(100 \%)$ & \\
\hline \multirow[t]{3}{*}{ Disease duration } & $<8$ days & $208(67 \%)$ & $181(33 \%)$ & $389(100 \%)$ & \multirow{3}{*}{$\begin{array}{l}0.0000001 \\
\left(X^{2}=250.5\right)\end{array}$} \\
\hline & 8 to 14 days & $8(13 \%)$ & $56(87 \%)$ & $64(100 \%)$ & \\
\hline & $>14$ days & $4(22 \%)$ & $14(78 \%)$ & $18(100 \%)$ & \\
\hline
\end{tabular}




\begin{tabular}{|c|c|c|}
\hline Criteria & $\begin{array}{c}\text { Vaccinated } \\
\text { N (\%) }\end{array}$ & $\begin{array}{c}\text { Unvaccinated } \\
\qquad N(\%)\end{array}$ \\
\hline No complications & $187(85 \%)$ & $178(70.9 \%)$ \\
\hline Pneumonia & $29(13.2 \%)$ & $67(26.7 \%)$ \\
\hline Meningitis & 0 & $1(0.4 \%)$ \\
\hline Convulsions & $3(1.4 \%)$ & $2(0.8 \%)$ \\
\hline Hepatitis & $1(0.4 \%)$ & 0 \\
\hline Death & 0 & $3(1.2 \%)$ \\
\hline Total & 220 & 251 \\
\hline
\end{tabular}

\section{CONCLUSION}

1. The percentage of measles cases between 1 to 5 years of age were significantly higher than other age groups despite vaccination for measles at 9 months.

2. Percentage of measles cases in female children who were vaccinated for measles was significantly higher as compared to those who were unvaccinated.

3. The percentage of cases showing significantly shorter duration of symptoms and complications was among those who were vaccinated as compared to those who were not vaccinated for measles.

\section{ACKNOWLEDGEMENT}

I want to thank my guide Late Dr. Ratnendra Shinde for giving the conceptualization to this article and providing his valuable inputs for this study.

\section{CONFLICT OF INTEREST}

The authors declare no conflict of interest.

\section{ABBREVIATIONS}

WHO: World health organization; $\mathbf{X}_{2}$ - Chi square value.

\section{SUMMARY}

A retrospective record based study which demonstrated that a significant percentage of children despite immunization suffered from measles. Age, gender and nutrition were found to play a vital role in acquisition of measles both in the vaccinated and unvaccinated children.

\section{REFERENCES}

1. Key facts [Internet]. 2018; p. 1-7. Available from: http://www.who.int/newsroom/fact-sheets/detail/measles

2. R G, TV. Audit of Measles Infection in Children From a Tertiary Hospital. Indian Pediatrics. 2009; 46(1): 81- 2.

3. Faneye AO, Adeniji JA, Olusola BA. Measles Virus Infection Among Vaccinated and Unvaccinated Children in Nigeria. Viral Immunology. 2015; 28(6): 304-8.

4. Nkowane BM, Bart SW, Orenstein WA, Baltier M. Measles Outbreak. Am J Public Health. 1987; 77(4): 434-8.

5. Bhaskaram P, Balakrishna N, Goud B, Sukanya M. Post vaccination scenario of measles : a retrospective analysis . Natl Med J India. 1999; 12(3): 111-2.

6. Sharma M, Bhatia $V$, Swami $H$. Outbreak of measles amongst vaccinated children in a slum of Chandigarh. Indian Journal of Medical Sciences. 2004 58(2): 47-53.

7. The Work of WHO in the Eastern Mediterranean Region Annual Report of the Regional Director 2014 [Internet]. 2012. 1-68 p. Available from: http://applications.emro.who.int/docs/RD_Annual_Rep_2015_16491_EN.pdf

8. Mishra A, Mishra S, Marathe N. Practical Observations from an Epidemiological Investigation of a Measles Outbreak in a District of India. Indian Journal of Community Medicine. 2018; 34(2): 117-21.

9. Mitchell P, Turner N, Jennings $L$, Dong $H$. Previous vaccination modifies both the clinical disease and immunological features in children with measles. Journal of prim health care. 2013; 5(2): 93-8.

10. Sudfeld C, Hasley N. Measles Case Fatality Ratio in India: A Review of Community Based Studies. Indian Pediatrics. 2009; 46(11): 983-9. 